\title{
REAL TIME CONTROL OF THE SEWER SYSTEM OF BOULOGNE BILLANCOURT A CONTRIBUTION TO IMPROVING THE WATER QUALITY OF THE SEINE
}

\author{
Emmanuel Kopecny¹ , Stéphane Entem¹, Antoine Lahoud1', Arne Moeller ${ }^{2}$, Lars Yde ${ }^{2}$, \\ Marc Soulier ${ }^{3}$ \\ 1 SAFEGE, 15/27 rue du Port, 92007 Nanterre, France \\ 2 DHI Water E Environment, Agern Allé, DK - 2970 Horsholm, Denmark \\ ${ }^{3}$ Conseil Général des Hauts-de-Seine, 4, avenue Benoît Frachon, 92015 Nanterre, France
}

\begin{abstract}
Confronted with the problem of overflows from its combined sewer system into the River Seine during rainfall, the Department of the Hauts de Seine (which covers some thirty urban districts on the west side of Paris) has decided to implement the real time control of its sewer system in 1996. To initiate this plan, as the town of Boulogne Billancourt seemed to be a particularly favourable site for the use of such techniques, a project to control its sewer system in real time has been implemented within the scope of the SPRINT 226 programme financed by the European Community.

The preliminary studies, based on a MOUSE computer model of the sewer system, showed that the real time control of the sewer network under study had a high potential benefit, since it would allow an $80 \%$ reduction of the volumes of waste water discharged into the Seine annually in the study zone. Following on from these encouraging results, the installation of a complete real time control system was set in hand. The system, at present undergoing testing and evaluation, consists principally of a MOUSE ON LINE real time model and a system for forecasting rainfall by means of radar images.
\end{abstract}

\section{KEYWORDS}

Combined sewer overflows; design tools; forecast model; MOUSE; on-line model; real time control; SPRINT european project. 


\section{I - REAL TIME CONTROL - A SOLUTION FOR THE PARIS REGION ?}

The sewer systems of the Paris region, like those of many large French and European cities are mostly of the combined type and were designed several decades ago (in the last century for those of central Paris) to meet two main objectives :

- to collect waste water and after its depollution in a treatment plant to discharge it into the receiving waters;

- to evacuate rainfall as quickly as possible, in order to reduce as far as possible the risk of flooding of built-up areas.

Intended above all to protect the population, such systems have subsequently proved to be not very effective from the point of view of the quality of the receiving waters, much of the potential benefit of the treatment of the waste water being cancelled out by the overflows of sewage during rain storms. Furthermore, the extension of built-up areas and thus of the impervious surfaces has amplified the problem of water quality and also increased the risks of flooding during rain.

Such more and more frequent disorders and malfunctions are ill accepted by the public (particularly when there are heavy summer rain storms which can lead to the death of a lot of fish in the river) and are in conflict with recent legislation which imposes heavy constraints on overflows from combined sewer systems.

In order to resolve these problems, a first approach could consist in increasing the size of the sewers and creating large storage volumes and treatment capacities to deal with the excess water in rainy weather. This type of development is often very difficult to do in an already built up zone and requires heavy investments.

Before setting off in this direction, it thus seems worthwhile to try to use the existing system better, in particular by controlling the storm overflow structures which are the key points of the sewer system of the Paris region. This control can take the form of local control systems which would be totally independent of the type of rainfall event encountered. But better still, it could involve a veritable real time control system taking into account the whole of the parameters (rainfall intensity, flows in the network, quality of receiving waters, treatment capacity of the treatment plant etc.). This would allow to continuously define an optimum mode of management of the various control devices, in order to meet the objectives laid down.

\section{II - THE BOULOGNE BILLANCOURT PROJECT}

The Department of the Hauts de Seine, which contains some thirty urban districts situated on the west side of Paris, is in charge of the primary sewer network covering its territory. This network, of the combined type, has many storm overflow structures and thus contributes to the deterioration of the water quality of the Seine in rainy weather.

Being conscious of these problems, the Departmental Authority wishes to improve the functioning of its sewer system during wet weather, especially by calling upon the most 
recent techniques of real time control. The urban district of Boulogne Billancourt has proved to be an particularly suitable site to initiate this project for the following reasons :

- under standard conditions (normal rainfall), the network seemed to have available storage capacity which was not used until now.

- the details of the sewer system are well known;

- there are already many measuring points on the network which are connected to a SCADA system (System of Control and Data Acquisition);

- some of the storm overflow structures were already fitted with automated movable weirs;

Thus the objective of the Boulogne Billancourt project, entrusted to the consortium SAFEGE - DHI, was to demonstrate the potential advantages of a real time control system, and then to implement the complete system to concretise the expected benefits.

Finally, this project is part of the wider European programme SPRINT 226, devoted to the real time control sewer systems. As well as Boulogne Billancourt, SPRINT 226 concerns eight cities of the European Community :

- Copenhagen (Denmark),

- Mantova (Italy),

- Verona - Lake Garda (Italy),

- Genoa (Italy),

- Bolton (United Kingdom),

- Berlin - Friedrichshagen (Germany),

- Vitoria-Gasteiz (Spain),

- Goteborg (Sweden).

\section{III - THE SEWERAGE SYSTEM OF BOULOGNE BILLANCOURT}

The primary sewer network of Boulogne Billancourt, of the combined type, is composed of large ovoid section visitable trunk sewers (up to three metres high). The whole of these trunk sewers constitutes a closely interconnected and very dense network.

The waste water and rainfall runoff collected are directed to the low part of the town, the quays bordering the Seine (see figure 1). The right bank departmental trunk sewer, situated below these quays, receives all this water which is subsequently transferred to the left bank departmental trunk sewer through two siphons. As well as the inflows from Boulogne Billancourt, the left bank trunk sewer receives inflows from the neighbouring towns of Issy-les-Moulineaux, Meudon, Sêvres, Saint-Cloud and Suresnes. 


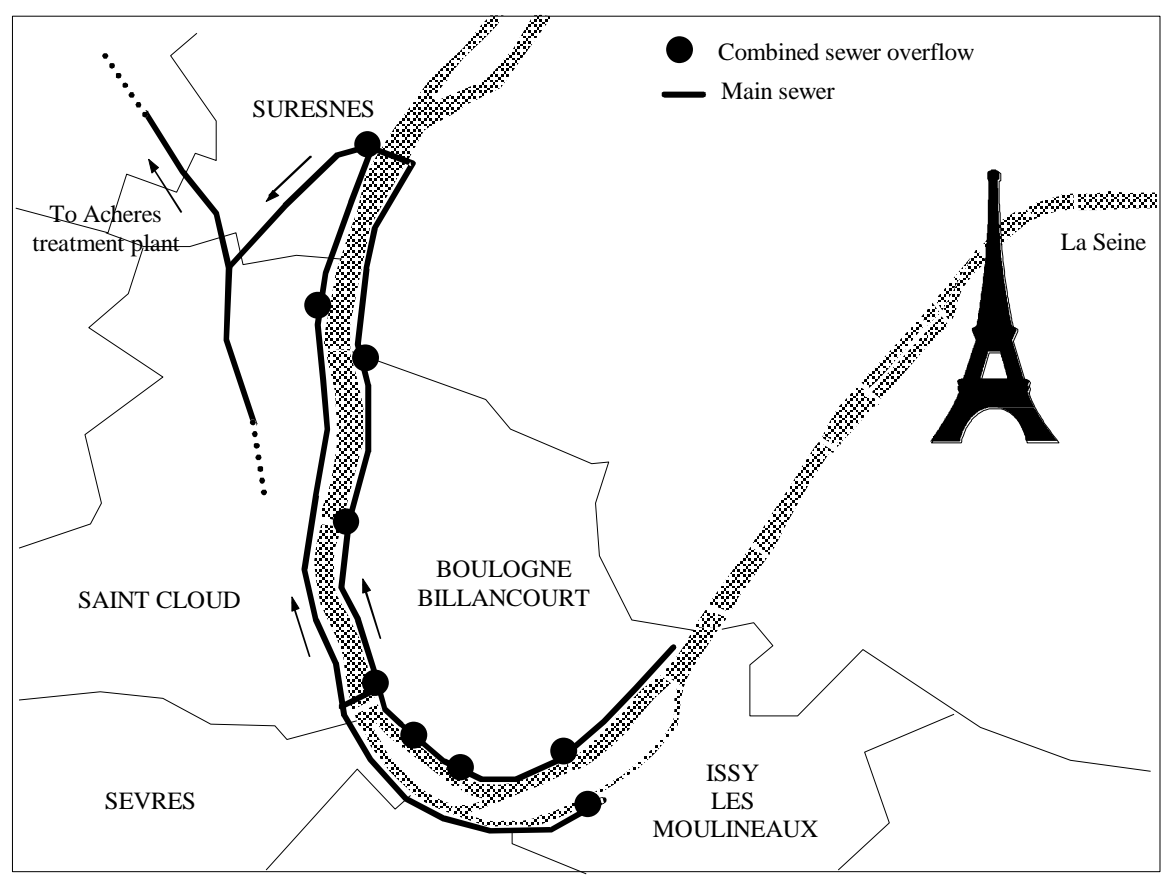

Figure 1: Boulogne-Billancourt area

This trunk sewer directs the flow thus collected towards the north of the study zone and discharges it into the Suresnes trunk sewer whose capacity is limited to about $3.5 \mathrm{~m}^{3} / \mathrm{s}$. The Suresnes trunk sewer afterwards joins the Sêvres-Achères trunk sewer which takes the waste water to the Achères Sewage Treatment Plant which treats the flow from nearly three quarters of the Paris region.

The capacity for evacuation of the waste water collected from the study zone towards the treatment plant is thus limited with respect to its flow rate, and the excess water in wet weather is therefore discharged into the Seine by ten storm overflow structures located on the two trunk sewers along the two banks of the Seine.

\section{IV - THE PRELIMINARY STUDY : IS REAL TIME CONTROL NEEDED?}

\section{IV.1 - The objectives}

The aim of the Department of Hauts de Seine is to reduce, as much as possible, the combined sewer overflows. The study zone of Boulogne Billancourt has all the characteristics of a suitable site for setting up a real time control system able to achieve this goal, but it is still of prime importance to begin with answering the following questions :

- Should this system be a predictive system, able to forecast the impact of a rainfall in the sewerage system and thus to adapt the control devices set points?

- Would a reactive real time control system, that is to say to install storm overflows with movable weirs commanded by local control systems (PID type regulations intended to maintain a limit level in the sewer network), not be sufficient? 
- What are the potential gains to be derived from controlling the storm overflow structures in terms of waste water volumes and pollution loads discharged into the Seine in wet weather?

- Does this type of control not risk provoking floods which did not occurr in the past, under similar rainfall conditions?

- Is it necessary to control all the storm overflow structures of the study zone?

- What types of set point should be applied to the storm overflow structures which it is desired to control?

For this reason, a preliminary study, based on a modelisation, is of fundamental importance for this type of project. The model constructed for this purpose can subsequently constitute the core of a control system based on a real time model, which was the case for the Boulogne Billancourt project.

\section{IV.2 - The tools of the MOUSE family}

Since a few years ago, the MOUSE software system has been enlarged, in particular to meet the new demands imposed by the more and more widespread will to control the functioning of sewer systems.

Thus some new modules have been added to the well known standard MOUSE :

- MOUSE NAM - an advanced hydrological model for long term simulations;

- MOUSE RTC - intended for analyses of potential for Real Time Control application and hydrodynamic long term simulations;

- MOUSE TRAP - a suite of computational models for the simulation of sediment transport and water quality in urban catchments and sewer systems;

- $\quad$ MOUSE SIMULATOR - for the emulation of the on-line environment and for testing the dynamic, global, forecast-based control strategies;

- $\quad$ MOUSE ON LINE - for the model-based on-line control of urban drainage systems.

All of these tools were used to carry out the Boulogne Billancourt project : the first three for the preliminary studies and the last two for the final setting up of the real time control system.

\section{IV.3 - The results : a high potential benefit}

MOUSE simulations were carried out for typical design rainfall events and for a long series of actual rain storms (three years - 268 rainfall events). Various control strategies were tested and the strategy selected at the end of these calculations necessitates the control of six storm overflow structures (out of the ten which exist) of which five are already fitted with movable weirs.

This control strategy enables important benefits to be obtained : 
- reduction by nearly $50 \%$ of the volumes of waste water discharged into the Seine for the design rainfall of yearly frequency;

- reduction by $80 \%$ of the volumes discharged during the long series of real rainfall events which were simulated (3 years, 268 rainfall events, see Figure 2);

- reduction by $90 \%$ of the pollution load discharged during the long series of real rainfall events which were simulated (3 years, 268 rainfall events);

- division by 5 of the frequency of overflows.

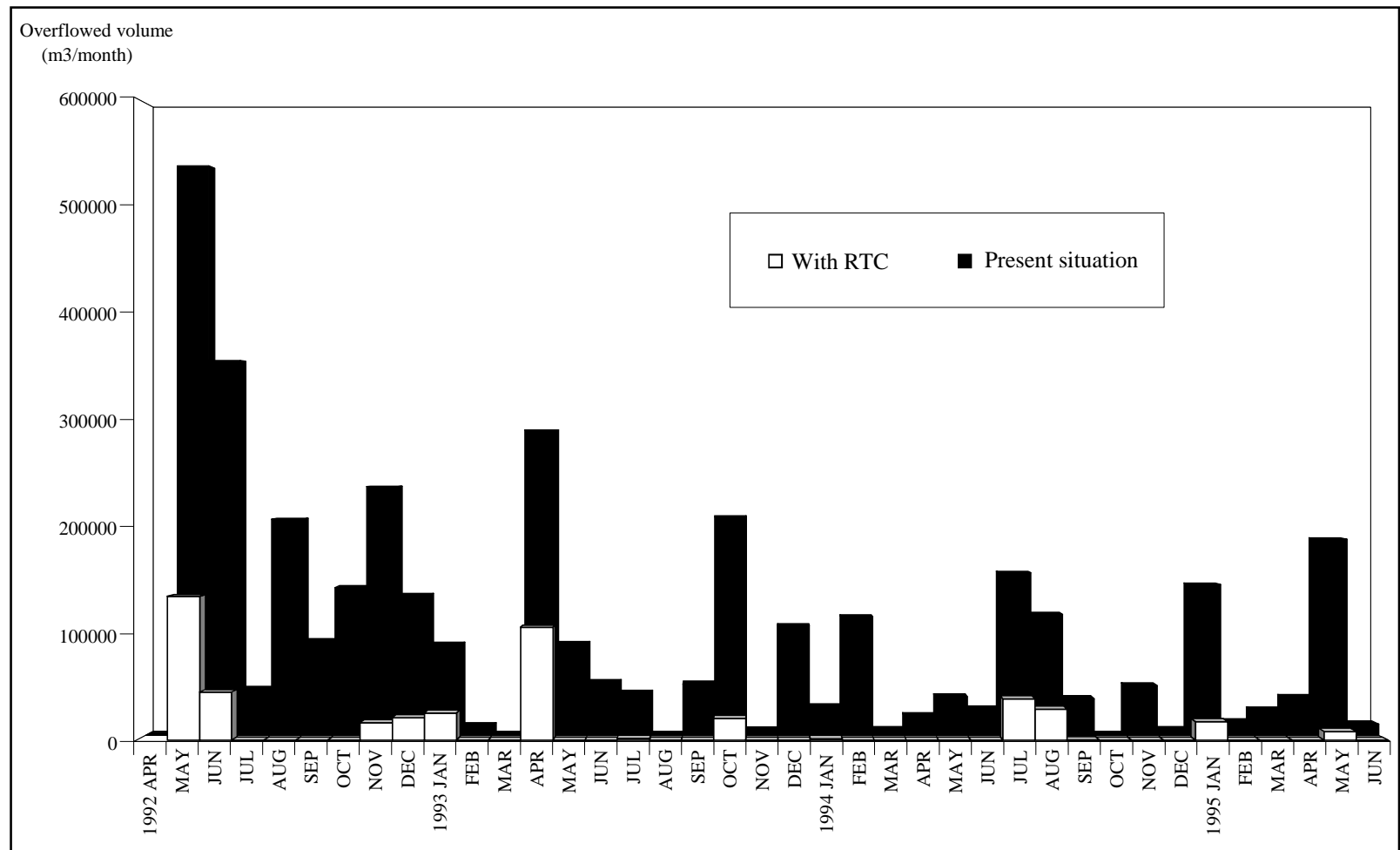

Figure 2: Discharged volumes into the Seine river - Results comparison with and without control system

The simulations carried out also showed that it was necessary to be able to change the set points applied to the controlled overflow structures, in order to modify them to suit the intensity of the rainfall event and thus not to provoke flooding during particularly heavy rainfall. Simple local control systems, with fixed set points, would thus not work in the case of Boulogne Billancourt, and a global and centralized control is therefore indispensable.

Furthermore, the rapidity of reaction of the sewer system also makes it necessary to incorporate an anticipatory aspect and the control system has to be based on forecasts of the rainfall and its impact on the sewer network (predictive real time control system). 


\section{V - THE SETTING UP OF THE REAL TIME CONTROL SYSTEM}

By the end of the preliminary study phase of the project, the interest of a real time control for this application had been demonstrated and the functionalities of the real time control system had been defined. The system implemented subsequently rests on five principal elements (see Figure 3).

- The 6 automated movable weirs control the overflows of waste water into the Seine. They are fitted with PID type regulation intended to maintain limit levels in the network. The whole object of the real time control system is to adjust the applied set point levels depending on the rainfall event taking place (6 control strategies have been defined).

- The MOUSE ON LINE real time model allows, thanks to its calculations, the impact of the measured rainfall on the sewer system to be forecasted since the delay between the precipitation and its impact on the storm overflow structures is of the order of 30 minutes. Moreover, it tests and chooses new set points in the case when the applied set points do not allow the fixed objectives to be satisfied (maintenance of a limit level in the network).

- The CALAMAR system of rainfall forecasting by interpretation of the National Meteorological Service's radar images enables the forecasting horizon of MOUSE ON LINE to be increased by one hour.

- The measurement points (rain gauges and measurements of level and flow rate) provide indispensable data for the functioning of MOUSE ON LINE.

- The SCADA system (GAIA) manages the transfer of data between the various components of the real time control system.

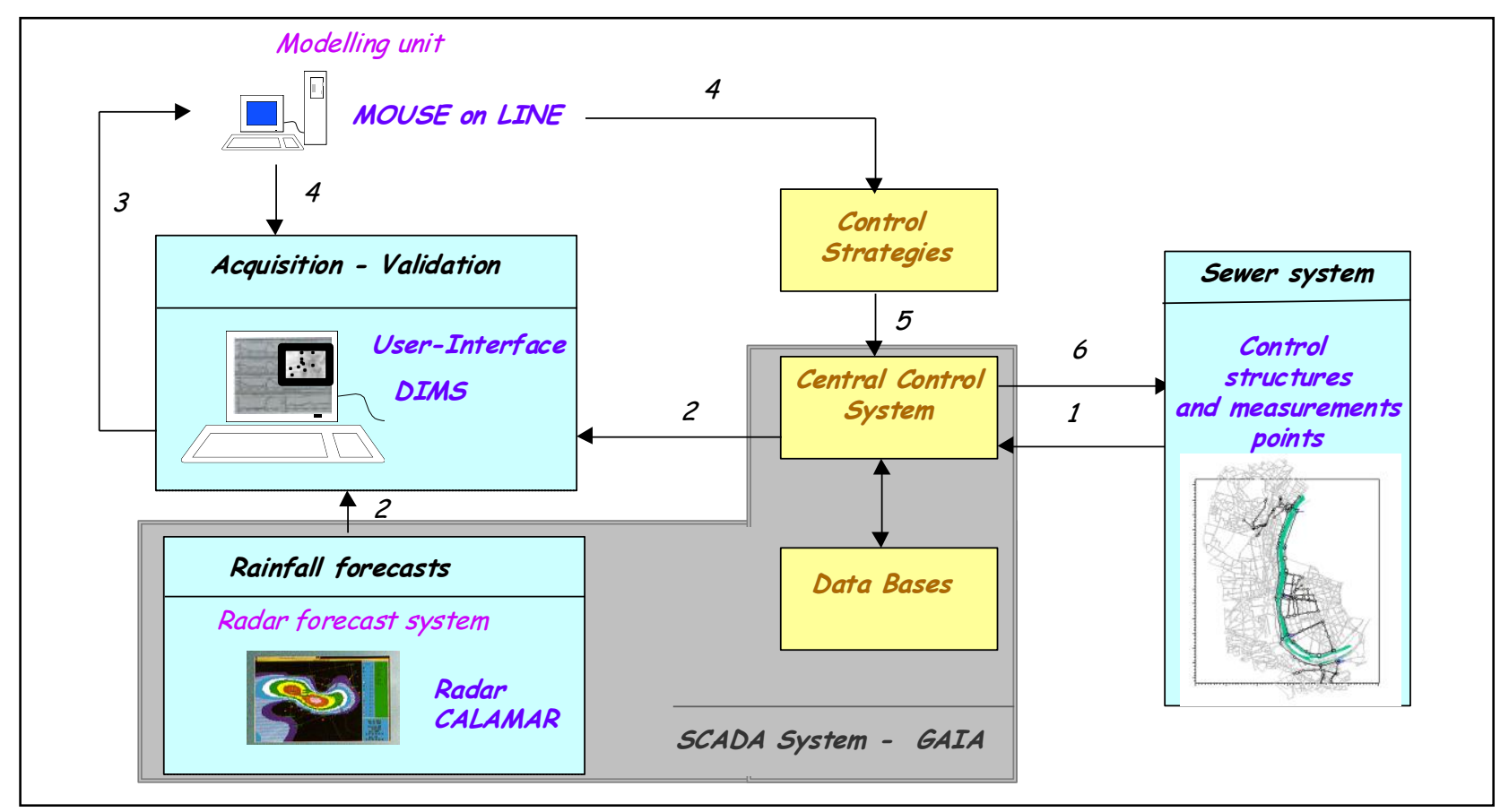

Figure 3: Simplified Mouse On line running diagram 
The cyclical running of the system turns on the following steps:

1- Data collection from the sewer system to GAIA (on line operation).

2- Data acquisition from GAIA to the DIMS user interface tool: 20 real measurements from the sewer system (water levels, weir crest levels, set points,...) are collected each minute. The rainfall forecasts are used each five minutes.

3- Data validation and formatting to be recognised and used by the modelling software MOUSE.

4- Determination, each five minutes, by iterative simulations, of the best control strategy to be applied to the network and storage of the hydraulic predicted values (one hourterm) into the DIMS data base.

5- Sending of the control strategy to GAIA.

6- Sending of the control strategy to the sewer system and application.

\section{VI - STATUS OF THE PROJECT}

The MOUSE ON LINE system has been integrated to the GAIA scada system in June 2000, linked with all the other existing components and started. The user interface (DIMS) has been defined with the help of the control room operators in order to fit the real needs (see example on figure 4).

It fully works at the present time by itself as a decision support structure and as a full real time control platform. On both cases, validation tests have been realised in on-line mode in order to run the system in the most accuracy way and to correct all the dysfunctions.

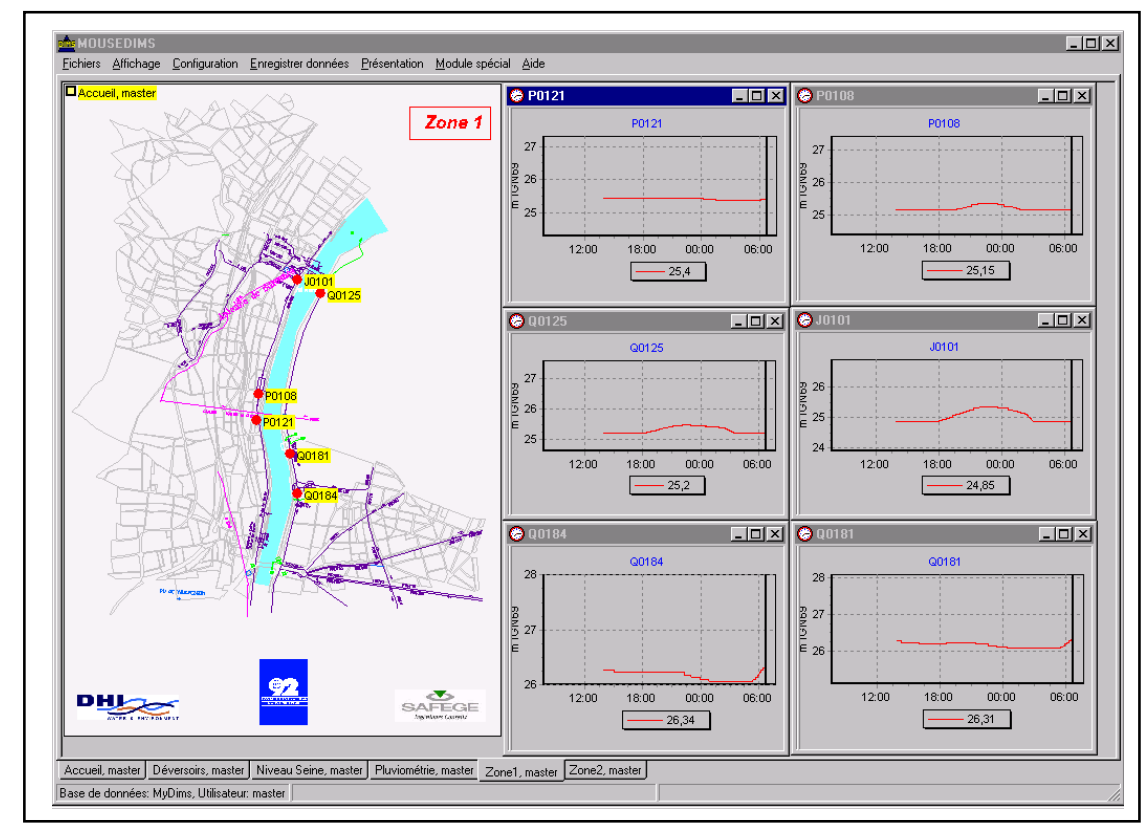

Figure 4: DIMS appearance - Example of window 
The validation phase showed a robust and trusted functionning of the system in terms of quality of prediction and generation of strategy, as it can appear in the examples on figure 5 .

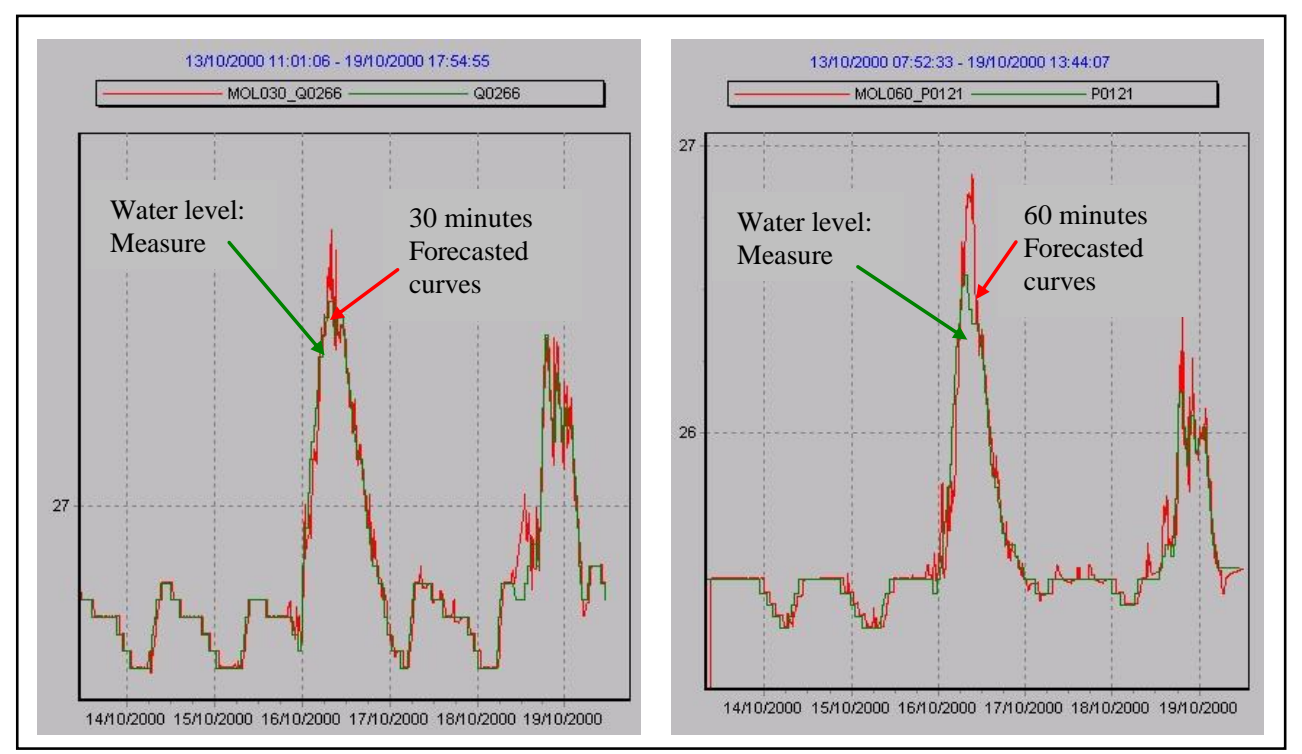

Figure 5: Comparison between real measurements and the Mouse On Line forecasted values

Subsequently, it would be possible to envisage the extension of the real time control system to the towns neighbouring Boulogne Billancourt, the final objective of the Department of the Hauts de Seine being to control the whole of the overflows of its sewer network into the Seine.

\section{REFERENCES}

Entem, S. Lahoud, A.(1996). Mise au point d'un système de contrôle en temps réel du réseau d'assainissement de la commune de Boulogne Billancourt. Study report p. 124.

Nielsen, J. B. Lindberg, S. Harremoes, P. (1993). Model based on-line control of sewer systems, 6th IAWQ workshop on instrument, control and automation, Banff, Canada

Nielsen, J. B. Tomicic, B. (1995). MOUSE software family - Heart of the RTC technology for urban drainage systems

Schilling, W. (1996). Potential and limitation of real time control, 7th international conference urban storm drainage, Hannover, Germany 